\title{
EVALUASI PENDUGAAN ANGKA PARTISIPASI KASAR PERGURUAN TINGGI TAHUN 2018 DENGAN SMALL AREA ESTIOMATION BENCHMARKING (STUDI KASUS DI PULAU JAWA)
}

\author{
EVALUATION OF ESTIMATING HIGH ROUND PARTICIPATION NUMBERS IN 2018 WITH \\ SMALL AREA ESTIOMATION BENCHMARKING \\ CASE STUDY IN JAVA ISLAND
}

\author{
Robert Kurniawan ${ }^{1}$, Dini Arifatin ${ }^{2}$, Amalia Noviani ${ }^{3}$, Fadhlullah ${ }^{4}$ \\ ${ }^{1}$ Politeknik Statistika STIS, Prodi. Komputasi Statistika, Jakarta. \\ 2,4Badan Pusat Statistik (BPS) RI, Subdit. Statistik Pariwisata, Jakarta. \\ ${ }^{3}$ Badan Pusat Statistik (BPS) RI, Subdit. Statistik Kesehatan dan Perumahan, Jakarta. \\ Alamat Korespondensi: \\ E-mail: ${ }^{1}$ robertk@stis.ac.id , 2 diniarifatin@gmail.com
}

\begin{abstract}
ABSTRAK
Selama ini, Angka Partisipasi Kasar Perguruan Tinggi (APKPT) yang merupakan salah satu target dari Sustainable Development Goal's (SDG's) disajikan oleh Badan Pusat Statistik (BPS) masih angka setiap Provinsi, dan untuk mendapatkan angka per kabupaten/kota sangat sulit. Hal ini terkendala jumlah sampel yang kurang memadai untuk dilakukan estimasi per kabupaten/kota. Sehingga untuk megestimasi sampai level area kecil dibutuhkan metode Small Area Estimation (SAE). Tetapi SAE pada area kecil dengan menggunakan metode Empirical Best Linear Unbiased Prediction (EBLUP) belum mampu mengatasi masalah agregasi area yang lebih besar, sehingga menyebabkan estimasi pada area kecil yang dihasilkan tidak konsisten dengan hasil estimasi langsungnya. Untuk mengatasi hal tersebut, maka digunakan metode EBLUP Benchmark untuk mendapatkan agregasi estimasi area kecil yang konsisten dengan estimasi langsung yang sudah ada. Misalnya hasil dari estimasi angka kabupaten/kota, jika di agregasikan, maka hasilnya sama dengan angka provinsi yang sudah di publikasikan terlebih dahulu. Sehingga pada penelitian ini bertujuan untuk mengevaluasi metode SAE Benchmark yang diaplikasikan untuk penghitungan estimasi APKPT di 6 provinsi Pulau Jawa. Hasilnya terlihat bahwa untuk provinsi yang jumlah kabupaten/kotanya banyak, seperti Jawa Barat, Jawa Tengah, dan Jawa Timur cenderung lebih bagus hasil estimasinya jika di hitung dengan SAE EBLUP Benchmark dibandingkan dengan SAE EBLUP. Cara menghitung ternyata juga berpengaruh dalam mendapatkan hasil estimasi. Berdasarkan caranya, dengan menghitung secara mandiri per Provinsi lebih bagus hasilnya dibandingkan dengan penghitungan berkelompok dan Nasional.
\end{abstract}

Kata kunci: Sustainable Development Goal's (SDG's), Small Area Estimation (SAE), Empirical Best Linear Unbiased Prediction (EBLUP), SAE Benchmark, Angka Partisipasi Kasar Perguruan Tinggi (APKPT).

\begin{abstract}
During this time, the Higher Education Rough Participation Rate (APKPT) which is one of the targets of the Sustainable Development Goal (SDG's) presented by the Central Statistics Agency (BPS) is still a figure for each Province, and to get figures per district/city is very difficult. Choosing the sample is constrained by the inadequate number of samples to be estimated by district/city. So to estimate up to the level of a small area required the Small Area Estimation (SAE) method. But SAE in a small area using the Empirical Best Linear Unlock Prediction (EBLUP) method has not been able to overcome the problem of aggregation of larger areas, causing the estimation of the small area produced to be inconsistent with the results of its direct estimation. The EBLUP Benchmark method is used to obtain a small area estimation aggregation that is consistent with existing direct estimates. For example the results of the estimated district/city figures, if aggregated, the results are the same as the provincial numbers that have published in advance. So this research aims to evaluate the SAE Benchmark method which is applied to calculate the APKPT estimation in 6 provinces of Java Island. The results show that for provinces with a large number of regencies/cities, such as West Java, Central
\end{abstract}


Java, and East Java, the estimation results tend to be better when calculated with the SAE EBLUP Benchmark compared to the SAE EBLUP. How to calculate it turns out also influential in getting estimation results. Based on the method, by counting independently per Province the results are better compared to group and National calculations.

Keywords: Sustainable Development Goal's (SDG's), Small Area Estimation (SAE), Empirical Best Linear Unbiased Prediction (EBLUP), SAE Benchmark, the Higher Education Rough Participation Rate (APKPT)

\section{PENDAHULUAN}

Sustainable Development Goal's (SDG's) adalah sebuah aksi untuk mengurangi kemiskinan, ketimpangan, dan menjaga lingkungan hidup yang berisi 17 tujuan dengan 169 target yang telah disepakati oleh para pemimpin dunia, termasuk Indonesia. Aksi tersebut direncanakan dapat tercapai di tahun 2030. Salah satu tujuannya yaitu memastikan pendidikan yang merata dan menyeluruh, dengan kualitas kesempatan belajar yang sama untuk semua lapisan masyarakat. Salah satu indikator dari yang ditargetkan adalah Angka Partisipasi Kasar Perguruan Tinggi (APKPT).

Selama ini, APKPT yang disajikan oleh Badan Pusat Statistik (BPS) masih angka setiap Provinsi, dan untuk mendapatkan angka per kabupaten/kota sangat sulit. Hal ini terkendala jumlah sampel yang kurang memadai untuk dilakukan estimasi per kabupaten/kota. Sehingga untuk megestimasi sampai level area kecil dibutuhkan metode Small Area Estimation (SAE). Tetapi SAE pada area kecil dengan menggunakan metode Empirical Best Linear Unbiased Prediction (EBLUP) belum mampu mengatasi masalah agregasi area yang lebih besar (Tzadivis, 2018), sehingga menyebabkan estimasi pada area kecil yang dihasilkan tidak konsisten dengan hasil estimasi langsungnya.

Untuk mengatasi hal diatas, maka digunakan metode EBLUP Benchmark untuk mendapatkan agregasi estimasi area kecil yang konsisten dengan estimasi langsung yang sudah ada (Rauf, 2019). Misalnya hasil dari estimasi angka kabupaten/kota, jika di agregasikan, maka hasilnya sama dengan angka provinsi yang sudah di publikasikan terlebih dahulu. Sehingga pada penelitian ini bertujuan untuk mengevaluasi metode SAE Benchmark yang diaplikasikan untuk penghitungan estimasi APKPT di 6 provinsi Pulau Jawa.

\section{METODE}

Estimasi Direct (langsung) menurut Rao (2003) merupakan suatu nilai estimasi yang berasal dari unit sampel yang dipilih menggunakan suatu metode pengambilan sampel tertentu dalam suatu wilayah atau domain dan tidak mampu memberikan keakuratan yang sukup dengan sampel kecil, sehingga mengakibatkan variansinya besar dan bias, serta hasilnya tidak dapat mewakili populasi yang sebenarnya. Sedangkan SAE merupakan salah satu metode statistik untuk menghasilkan subpopulasi (area) dari populasi yang sampel yang terbatas, dan ukurannya tidak memenuhi atau tidak ada sampel yang mewakili (Rao dan Molina, 2015).

Henderson (1953) memperkenalkan metode untuk mendapatkan estimasi random effects pada linear mixed models, yang biasa disebut Best Linear Unbiased Predictor (BLUP). Kemudian Rao dan Molina (2015) mengusulkan perbaikan dari model BLUP yang memiliki kekurangan, yaitu masih tergantung pada komponen varians area dan estimasinya menggunakan Maximum Likelihood(ML), diperbaiki dengan menggunakan Restricted Maximum Likelihood (REML). Dengan menggunakan REML diharapkan estimator yang terbentuk tetap unbiased walaupun sampelnya tetap kecil. Metode tersebut sering disebut dengan EBLUP.

Persamaan dari estimator BLUP sebagai berikut:

$$
\tilde{\theta}_{i}^{H}=\boldsymbol{x}_{i}^{T} \widetilde{\boldsymbol{\beta}}+\gamma_{i}\left(\hat{\theta}_{i}-\boldsymbol{x}_{i}^{T} \widetilde{\boldsymbol{\beta}}\right)=\gamma_{i} \hat{\theta}_{i}+\left(1-\gamma_{i}\right) \boldsymbol{x}_{i}^{T} \widetilde{\boldsymbol{\beta}}
$$

dimana 


$$
\widetilde{\boldsymbol{\beta}}=\widetilde{\boldsymbol{\beta}}\left(\boldsymbol{\sigma}_{u}^{2}\right)=\left[\sum_{i=1}^{m} x_{i} \boldsymbol{x}_{i}^{T} /\left(\sigma_{u}^{2} z_{i}^{2}+\psi_{i}\right)\right]^{-1}\left[\sum_{i=1}^{m} x_{i} \hat{\theta}_{i} /\left(\sigma_{u}^{2} z_{i}^{2}+\psi_{i}\right)\right],
$$

dan $y_{i}=\sigma_{u}^{2} z_{i}^{2} /\left(\sigma_{u}^{2} z_{i}^{2}+\psi_{i}\right)$ dengan menggunakan REML untuk mengestimasi $\sigma^{2}$ serta mensubstitusikan $\hat{\sigma}_{u}^{2}$ ke $\sigma_{u}^{2}$, sehingga terbentuk Empirica/BLUP (EBLUP)

$$
\hat{\theta}_{i}^{H}=\hat{\gamma}_{i} \hat{\theta}_{i}+\left(1-\hat{\gamma}_{i}\right) \boldsymbol{x}_{i}^{T} \widetilde{\boldsymbol{\beta}}
$$

Rao dan Molina (2015) menyatakan kekurangan dari EBLUP yang tidak dapat menghasilkan agregasi nilai estimasi yang menjamin kekonsistenan dengan nilai estimasi level area diatasnya. Oleh karena itu, dibutuhkan metode SAE yang dapat menghasilkan estimasi yang konsisten dengan level area yang lebih tinggi. Metode tersebut dikenal dengan SAE Benchmarking.

Misalkan $\theta_{i}$ adalah nilai rata-rata untuk wilayah $\mathrm{i}$, dan $\theta_{+}=\sum_{l=1}^{m} W_{l} \theta_{l}$ adalah agregasi ratarata, dimana $W_{l}=\frac{N_{l}}{N}$ adalah penimbang untuk masing-masing area. Pada masing-masing area yang tersampel, maka $\sum_{l=1}^{m} W_{l}=1$.

Misalkan suatu estimasi langsung $\hat{\theta}_{+}=\sum_{l=1}^{m} W_{l} \hat{\theta}_{l}$ dari $\theta_{+}$yang bersifat reliable, maka estimasi area kecil $\theta_{i}$ diharapkan agar saat diagregasikan akan sesuai dengan estimasi langsung yang sudah reliable $\hat{\theta}_{+}$(Rao dan Maolina 2015).

$$
\hat{\theta}_{+}-\sum_{l=1}^{m} W_{l} \hat{\theta}_{l}^{H}=\sum_{l=1}^{m} W_{l}\left(1-\hat{\gamma}_{l}\right)\left(\hat{\theta}_{l}-\boldsymbol{x}_{i}^{T} \widehat{\boldsymbol{\beta}}\right) \neq 0
$$

sehingga perlu dilakukan modifikasi pada $\hat{\theta}_{i}^{H}$ agar benchmarking dapt dilakukan.

Sumber data pada penelitian ini menggunakan Survei Sosial Ekonomi Nasional (SUSENAS) 2018, dan Podes 2018. Karena belum ada software statistik yang dapat mengolah metode SAE, maka pengolahan dilakukan dengan menggunakan software R (Pramana, dkk, 2017) versi 3.6.1.

\section{HASIL DAN PEMBAHASAN}

Hasil dari penelitian ini menyatakan bahwa jika estimasi dilakukan secara terpisah untuk masingmasing provinsi, maka Relative Standart Error (RSE) dari EBLUP Benchmark hasilnya lebih rendah dibandingkan RSE langsung dan RSE EBLUP biasa (Gambar 1). Badan Pusat Statistik (BPS) (2014), menyatakan bahwa estimasi dengan nilai RSE $\leq 25 \%$, maka estimasi tersebut dianggap akurat (dapat digunakan). Pada Gambar 1 terlihat di DKI Jakarta pada Index Area 1 (Kepulauan Seribu) terlihat nilai RSE nya sangat tinggi untuk semua metode. Hal ini dikarenakan di Kepulauan seribu tidak terdapat Perguruan Tinggi (BPS, 2018), sehingga penduduknya banyak yang kuliah di Kabupaten/Kota lain. Tetapi secara umum, EBLUB Benchmark mampu menurunkan RSE dari estimasi langsung mau pun EBLUP.

Tetapi jika diolah secara bersamaan 6 provinsi di Pulau Jawa (Gambar 2), RSE yang dihasilkan menjadi berubah. Pengolahan per provinsi ada 5 Kabupaten/Kota yang RSE nya $\leq 25 \%$, sedangkan untuk pengolahan berkelompok menjadi 6 Kabupaten/Kota yang nilai RSE nya $\leq 25 \%$. Hal ini berarti, untuk pengolahan secara berkelompok pada indikator APKPT di Pulau Jawa kurang tepat. Hasil yang berbeda didapatkan jika 6 provinsi di Pulau Jawa, di olah secara bersamaan secara Nasional digabung dengan Kabupaten/Kota di seluruh Indonesia (Gambar 3). Hasil RSE yang nilainya $\leq$ $25 \%$ ada 13 Kabupaten/Kota. Hasil pengolahan secara Nasional pun kurang tepat untuk melihat nilai estimasi 6 Provinsi di Pulau Jawa.

Berdasarkan hasil diatas,dapat disimpulkan bahwa untuk provinsi yang jumlah kabupaten/kotanya banyak, seperti Jawa Barat, Jawa Tengah, dan Jawa Timur cenderung lebih bagus hasil estimasinya jika di hitung dengan SAE EBLUP Benchmark dibandingkan dengan SAE EBLUP dengan menghitung secara mandiri per Provinsi dibandingkan dengan penghitungan berkelompok dan Nasional. 


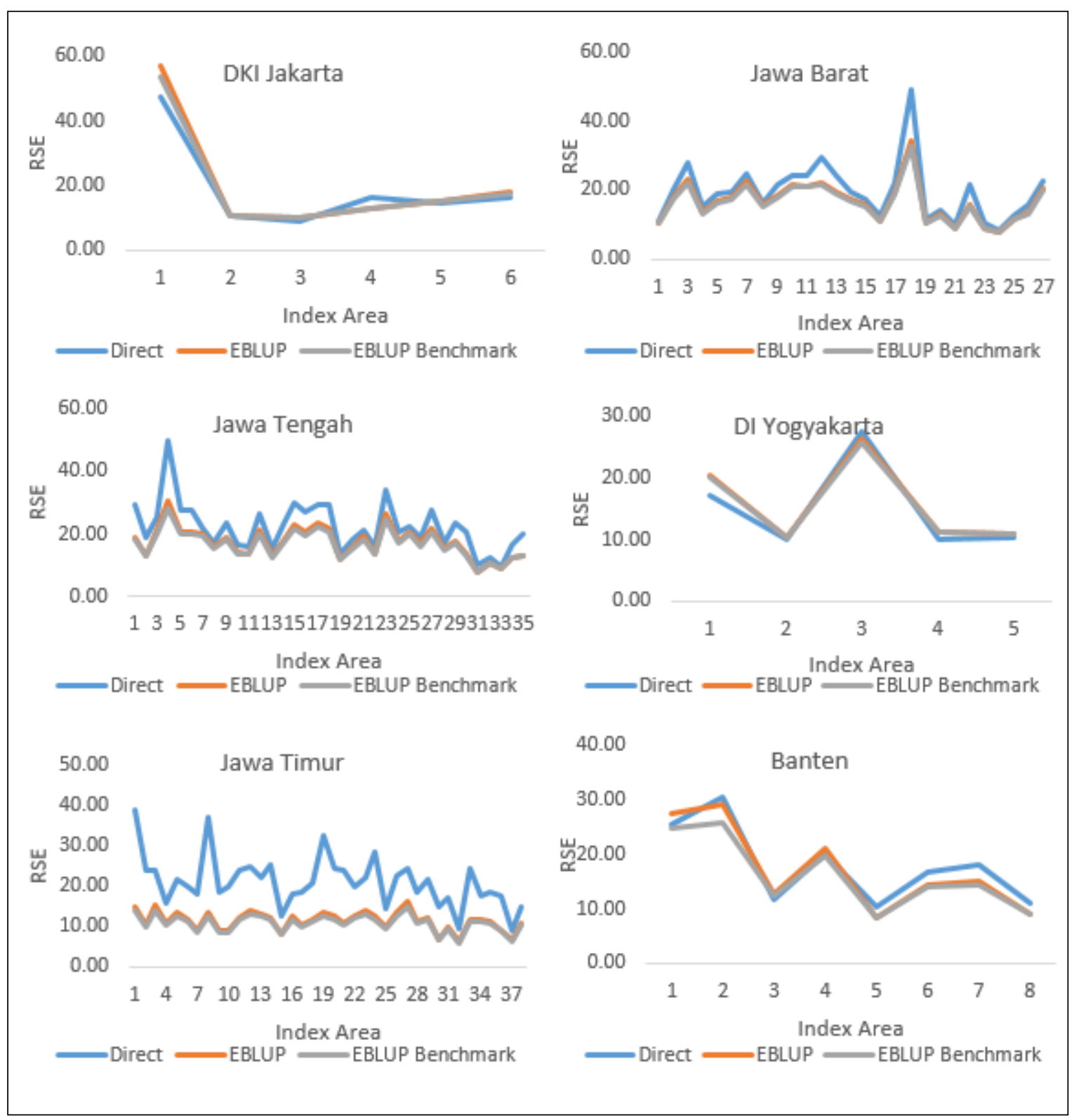

Gambar 1. RSE Estimasi Direct, EBLUP dan EBLUP Benchmark yang diolah per provinsi (6 Provinsi di Pulau Jawa)

Pada Gambar 1 diatas dapat dilihat provinsi Jawa Timur dengan jumlah Kabupaten/Kota sebanyak 38, ketika dilakukan pengolahan SAE EBLUP atau SAE EBLUP Benchmarking terlihat penurunan RSE yang cukup drastis. Beberapa wilayah yang memiliki RSE lebih dari $25 \%$ langsung menurun dibawah 20\%. Hal ini menunjukkan bahwa hasil dari EBLUP dan EBLUP Benchmarking lebih baik dibandingkan dengan estimasi langsung. Tetapi berbeda dengan provinsi DKI Jakarta, DI Yogyakarta, dan Banten yang memiliki jumlah kabupaten/kota kurang dari 10. Hasil dari pengolahan EBLUP dan EBLUP Benchmarking tidak menunjukkan performa yang baik, atau masih cenderung mengikuti pola dari RSE estimasi langsungnya.

Berbeda dengan Gambar 2, pengolahan dilakukan dengan serentak bersama-sama enam provinsi di Pulau Jawa. Provinsi dengan jumlah kabupaten/kota yang lebih dari 10 seperti provinsi Jawa Tengah, Jawa Barat, dan Jawa Timur, hasil RSE dari EBLUP dan EBLUP Benchmarking mengikuti pola RSE estimasi langsungnya. Metode SAE belum mampu menurunkan nilai RSE-nya. Tetapi pada provinsi DI Yogyakarta dengan 5 kabupaten/kota, performa dari EBLUP Benchmarkingnya mampu menurunkan nilai RSE. Di index area 3 yang RSE direct nya mendekati $30 \%$, pada RSE EBLUP Benchmarking menurun menjadi $10 \%$. 
DKI Jakarta

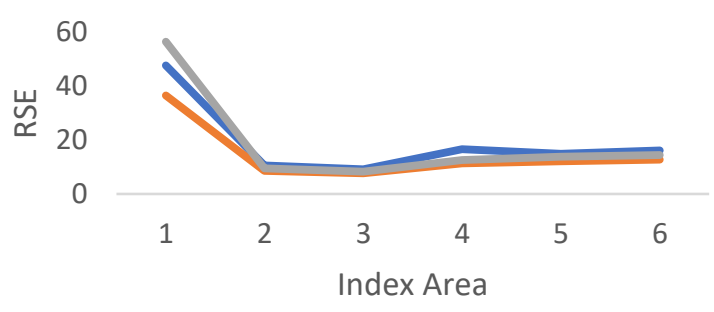

$\longrightarrow$ Direct $\longrightarrow$ EBLUP EBLUP Benchmark

Jawa Tengah

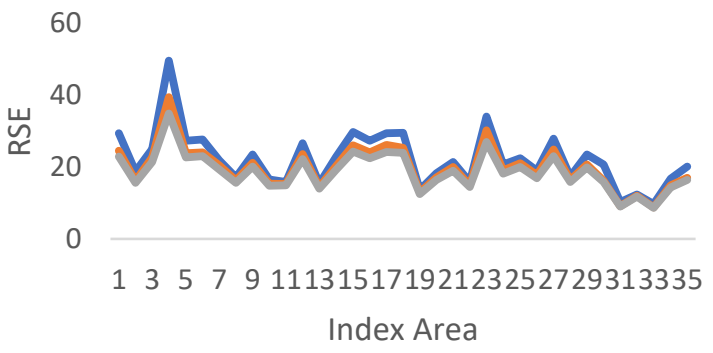

Direct $\longrightarrow$ EBLUP EBLUP Benchmark

Jawa Timur

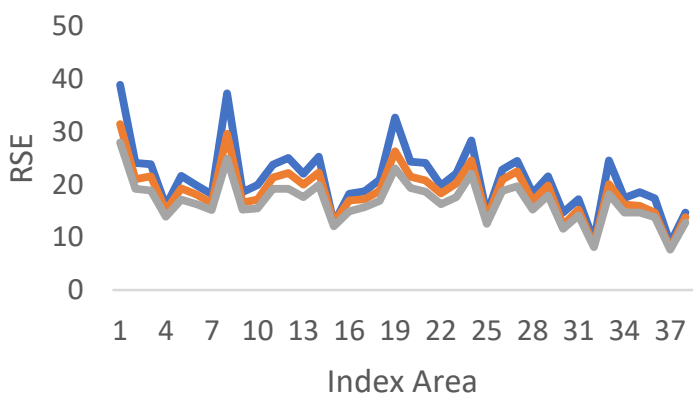

Direct $\longrightarrow$ EBLUP EBLUP Benchmark
Jawa Barat

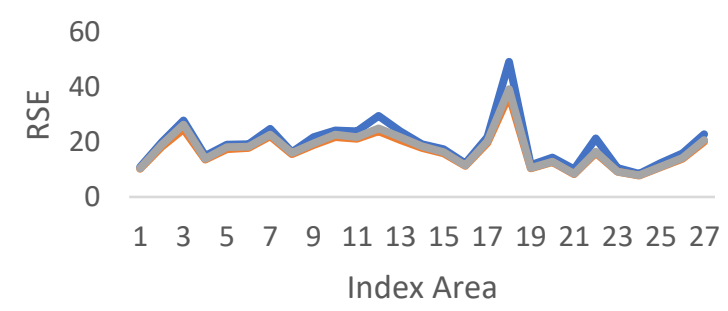

$\longrightarrow$ Direct $\longrightarrow$ EBLUP $\longrightarrow$ EBLUP Benchmark

DI Yogyakarta

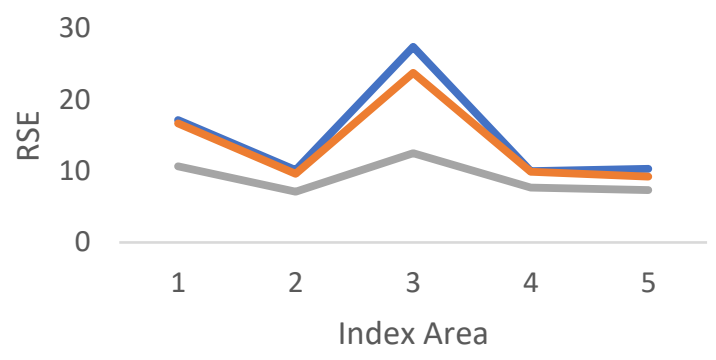

$\longrightarrow$ Direct $\longrightarrow$ EBLUP EBLUP Benchmark

\section{Banten}

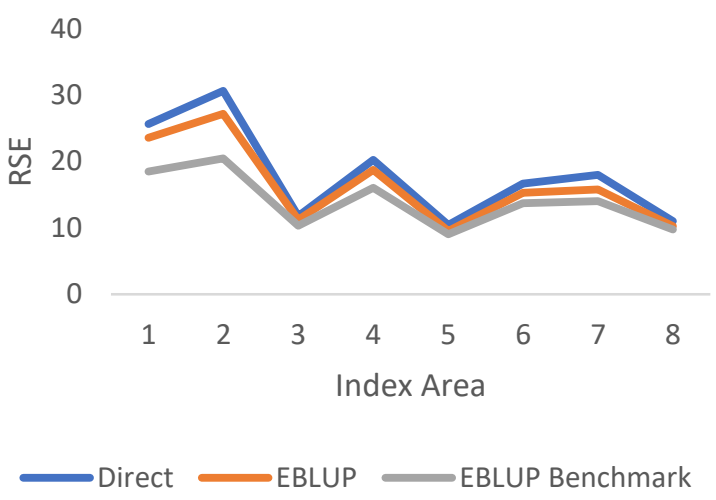

Gambar 2. RSE Estimasi Direct, EBLUP dan EBLUP Benchmark yang diolah bersamaan (6 Provinsi di Pulau Jawa)

Fenomena perbedaan hasil RSE dari cara pengolahan ini sejalan dengan Steorts dan Ghosh (2013) yang menyatakan bahwa metode SAE EBLUP Benchmark memiliki kekurangan yaitu faktor kali yang digunakan sama untuk semua penduga, sehingga tidak konsisten secara desain, tetapi MSE yang didapatkan sudah unbiased, dan dimungkinkan MSE-nya lebih besar dari MSE EBLUP. 
DKI Jakarta

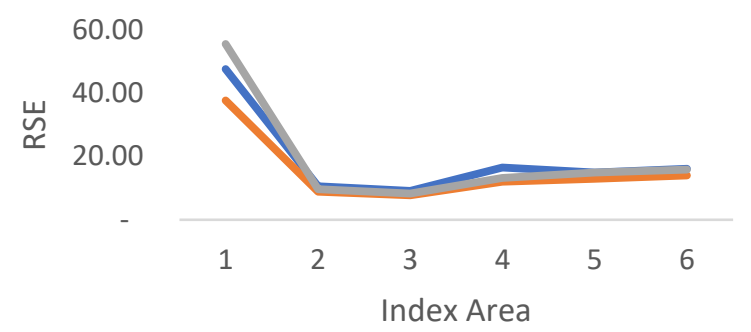

Direct —EBLUP EBLUP Benchmark

Jawa Tengah

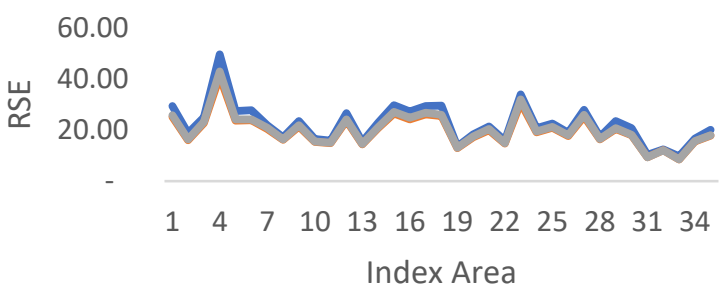

Direct $\longrightarrow$ EBLUP $\longrightarrow$ EBLUP Benchmark

Jawa Timur

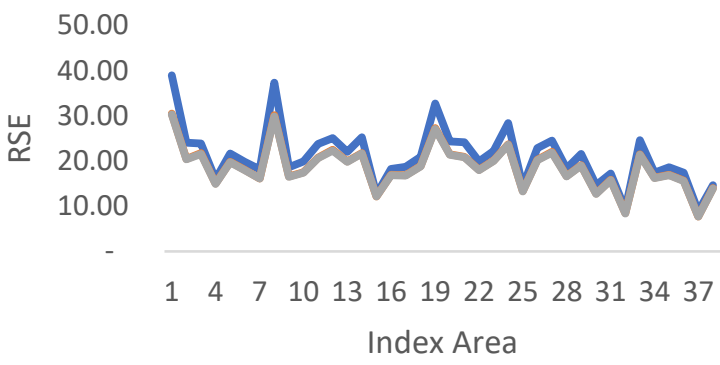

-Direct —EBLUP —EBLUP Benchmark

\section{Jawa Barat}

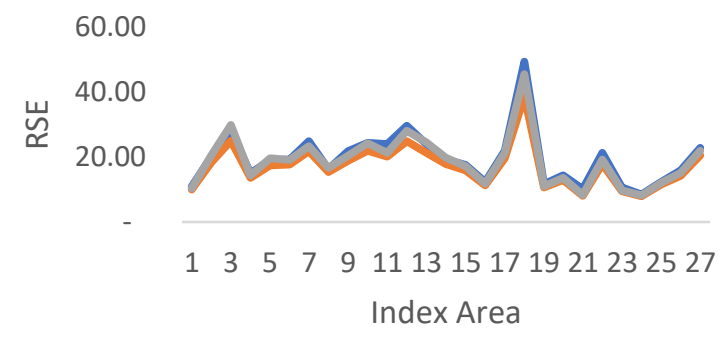

Direct EBLUP EBLUP Benchmark

DI Yogyakarta

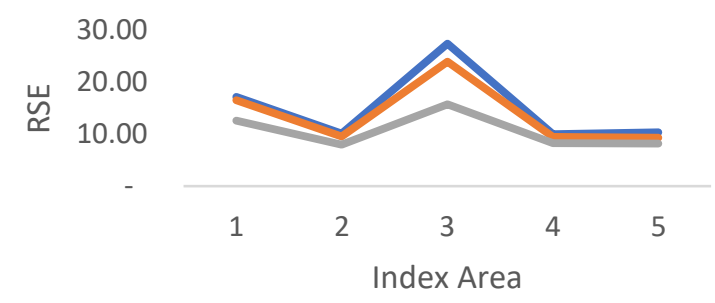

Direct EBLUP EBLUP Benchmark

\section{Banten}

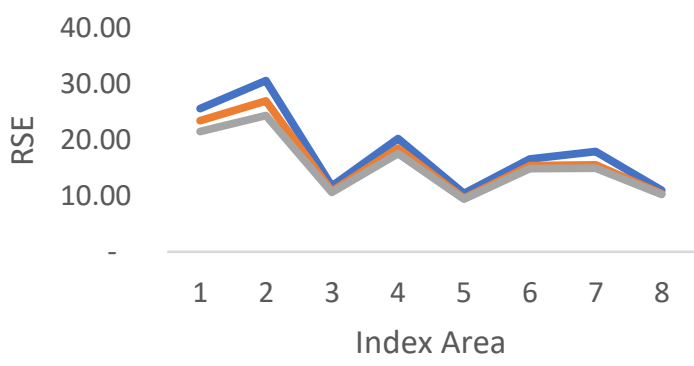

Direct $\longrightarrow$ EBLUP $\longrightarrow$ EBLUP Benchmark

Gambar 3. RSE Estimasi Direct, EBLUP dan EBLUP Benchmark yang diolah Nasional (6 Provinsi di Pulau Jawa)

\section{KESIMPULAN}

Berdasarkan pembahasan dan diskusi diatas, dapat disimpulkan bahwa pengolahan masingmasing Provinsi hasilnya menunjukkan hasil yang lebih bagus dibandingkan hasil dari pengolahan bersamaan baik secara kelompok atau nasional. Hal ini dikhususkan untuk provinsi besar dengan jumlah kabupaten/kota yang banyak, seperti Jawa Barat, Jawa Tengah, dan Jawa Timur. Kebaikan estimasi dilihat berdasarkan nilai RSE SAE Benchmark yang yang lebih kecil dibandingkan dengan RSE dari estimasi langsung. Sehingga dapat disarankan bahwa untuk proses mendapatkan estimasi SAE dapat melihat dari berbagai skenario perhitungan. Baik dilakukan secara mandiri (per provinsi) atau dilakukan secara bersama-sama dengan melihat performa dari RSE-nya. 


\section{DAFTAR PUSTAKA}

Tzavidis N, Zhang LC, Luna A, Schmid T, Rojas-Perilla N (2018). From Start to Finish: A Framework for the Production of Small Area Official Statistics. Journal of the Royal Statistical Society Series A, 181(4), 1-33

BPS (2014). Statistik Komuter Jabodetabek: Hasil Survei Komuter Jabodetabek 2014. BPS. Jakarta ...(2018). Statistik Potensi Kelurahan Provinsi DKI Jakarta 2018. BPS DKI Jakarta. Jakarta

Rauf, Aldi Saeful (2019). Pengembangan Aplikasi Small Area Estimation dengan Metode Benchmarking. Skripsi Politehnik Statistika STIS. Jakarta. $66 \mathrm{hlm}$.

Rao, J.N.K. \& Molina, I. (2015). Small Area Estimation Second Edition. NewYork: John Wiley and Sons, Inc. Rao, J. N. K. (2003). Small Area Estimation. New York: John Wiley and Sons, Inc.

Henderson, C. R. (1953). Estimation of variance and covariance components. Biometrics 9:226-252.

Pramana, S., Yordani, R., Kurniawan, R., \& Yuniarto, B. (2017). Dasar-dasar Statistika dengan Software R Konsep dan Aplikasi. Bogor: in media.

Steorts, R. C., \& Ghosh, M. (2013). On estimation of mean squared errors of benchmarked empirical Bayes estimators. Statistica Sinica, 749-767. 